\title{
The Space and the Time as a Nosological Query
}

Barbara Piozzini*
Unitre, Purdue, MIUR, Italy

*Corresponding author: Prof. Barbara Piozzini, Unitre, Purdue, MIUR, Italy; Email: filosofiastoriapiozzini@gmail.com

\section{Commentary}

Volume 4 Issue 1

Received Date: March 03, 2021

Published Date: March 16, 2021

DOI: $10.23880 /$ phij-16000167

\section{Abstract}

The aim of the paper is the one to circumbscribe the space and the time considered as epiphenomenical clusters of the matter in contemporary sciences.

From the inception, we are taking into consideration their physical dimension that is null when divided, thus, we are opening a dialogue regarding the Hypostatic tendecy of human beings to rationalize the methaphisical counterpart of the matter.

\section{Commentary}

The space and the time as a nosological query.

If we consider as a general statement the hystorical assumption derived from the Greeks on the basis of a worthy global inclusion of the space and the time mostly included in the concept of the environment, we would lack of the necessary acknowledgement to isolate and better to know the phenomenas we will deal with.

The Space and the time from the beginning of our history considered to be the necessary to meet evolution involve different queries; nevertheless, it derives from the Greeks the hypothesis, the latter evaluated in physicians studies such as Newton, Einstein or Wertheimer's one, to measure the space and the time to let them change from an absolute assertion to relativistic one, as a matter of fact, taking into consideration that to measure does not imply to contain or to quantify in order to make something objective but, on the contrary, it means to transform the risk of an abolutist perspective into a partial one.

If it is true that the multiple forms of reality need and imply the concept of mutation refered to a fixed space and time, it was with the paradox of the movement, structured to explain the changement of the phenomenas of reality, which was first demonstrated a divergence in mutation if observed from a sensorial nor from a rational point of view.
First of all, we have to point out the role of reasoning that was, at the time of the age we are considering, totally divided from sensorial perception; the aim of philosophical studies was, infact, the one to enlight and empower the usage of the reason including its relevant limits, we have thus to wait for the birth of a new concept of Philosophy and the birth of the scientific method to define sensorial and rational evaluation when quering reality.

As exposed above, during the greek ages, the attempt was the one to establish a relation between fixed and variable proprieties of reality, for example, in the case of some lights or the one of an arrow, if we consider the derivated qualia of their movement in the space and we postulate the space to be divisible, we'll fix their movement as empty if related to space; as a gnoseological evidence, the arrow will not move from $T 1$ and the appearance of its movement (as the one of some lights turned on and off in a sequence) will structure our knowledge. ${ }^{1}$

It was with the development of the Maths theory of Infinity the way throgout it had been explained the latter paradox; it had been demonstrated, infact, the sum of a defined numbers of quantity for unlimited times we'll not

1 Gentile, Ronga, Bertelli, Skepsis, Philosophy as research, La Filosofia come ricerca, dalle origini ad Aristotele, edizioni il Capitello, Torino, 2018; pp. 97-98 


\section{Philosophy International Journal}

necessary correspond to unlimeted one, that is to say, if we admit that the space and the time are divisible is due to observe their physical dimension is null.

From a naturalistic point of view, where the space and the time are involved in sensorial perception of reality, their structures has thus been outlined in line with the assumption of a measurement nullification; at this point, the maths' calculation become expression of a constitutional tendency of men to measure the variation when compared with fixed or null elements.

In addition, considering the time as a separated element from realism, Einstein definition would suggest us the present is everything simultaneous to the present in order to underline the zero quotation of the instant as well as the one of the space. ${ }^{2}$

The last passage is to introduce the concept of contraction of time and distances used, as an instance of principle, in the mechanique of quantum where even the presence of a mass, as the one of the fotonic expression, has no application.

If a critical reflection is conduced on the basis of a genesis of space and time, we have to take into consideration the influence of this factors in the costruction of a theory even if, as defined with Mach's theory, they represent an ipostatic tendecy of men to measure methaphisical entities not observable for their natural conformation ${ }^{3}$.

An Historical consideration is thus due to enhance the appercetion of this principle otherways to remain intrinsecal in science.

At this point, after in leaterature have been developed studies about the erroneous perception and the physical dimension of the before mentioned phenomenas, we'd like to introduce one of our main argument: are space and time considered as epiphenomenical factors in scientific and clinical context or, converselly as an absolute?

Considering medicine to be the science developed on the basis of previous scientific studies, we have to briefly consider first, its roots.

From the greek language pharmakòs, the ethimological dimension of the word include the blow in the past was considered to be demonic up to V b.c. untill Hyppocrates separeted the mythologycal dimension from the nosological

2 Castellani E. Morganti M, La Filosofia della Scienza, il Mulino, Bologna, 2019; pp. 201

3 Castellani E. Morganti M, La Filosofia della Scienza, il Mulino, Bologna, 2019; pp 84-85 level when trying to define its practical counterpart: tekhné is to aim at an inferential evaluation where the particular event is used to build an upper structure of knowledge ${ }^{4}$.

The nosognomic research in etiopathogenesis introduced by Hyppocrataes considers, infact, different signs, their relation and proportion with different causes to transform an immediate evidence into a Science ${ }^{5}$.

Moreover, in Hyppocratic medicine the space and the time in their genomics antrophological counterpart were considered, indeed, as particular geomorphic expression of an illness; such as immanent causes of expression of pahthology, thus, factors which conditioned the onset of it and its existence.

If we consider that, during the past ages, some pathologies were silent or different respect to the contemporaries one, according to Hyppocrates point of view, it would depend on the inclusion of geomorphical factors such as the Space, the Time and the habits become absolute: "In Scizia men were fat because, at birth, they were not treated with bands". ${ }^{6}$ Infact, the main divergence in the onset of an illness was not just dued to the technique but there were evidence, in Hyppocatic medicine, the seasons, geography, the way to think and the long lime term of life as well contributed to increase a clinical attitude, that is to translate, an immanentistic point of view in the manner to deal with the space and the time.

On the contrary, in contemporary medicine, the genomical expression of the space and the time themselves are mostly considered as epiphenomenical contingencies implied in science as far as the clinical etiopathogenesis and the nosological process in Biology is concerned: considered to be an isolable phenomena from pathogenesis the space and the time are mostly used both in Biology and in medicine such us referees and products of an illness and, when they are not, they generally contribute to define the attitude to develop a pathology.

Let us think of the organization of cells in space and time with subparts which are functional to a major mechanism, let's take into consideration the inflamatory process considered as secondary in the case of a possible impairment of an organ, the age of a man, the ribosomal response in proteical synthesis or the general way a pathologist anatom would consider time in terms of clinical convention postposted when related to a prior event; these are facts where we can

\footnotetext{
4 Armocida G. Bicheno E. Fox B, Storia della Medicina, Jaka Book, Milano, 1993 pp. 15-16.

5 Fanzago tr. It Perrone F. Isitutuzioni patologiche, seconda edizione, Da' Torchi di Luca Marotta, Napoli, 1824 pp 132. 6 Ibidem, p. 180.
} 


\section{Philosophy International Journal}

read the space and the time as epiphenomena.

Furthermore, there is a biological evidence of the difficulty to evaluate this phenomenas, readable within the concept of gradual trasmutation of a species into another.

As we mentioned before, biologically speaking, the concept of time and space are the necessary for the theory of evolution, where a scientist has to taxonomize a fenotypical generational change defined by clusters.

Species $^{7}$ has to be regarded as things that can evolve slowly from other species and have vague boundaries where the time show their limit. As a consequence, separation in the space and the reproduction of new characteristic in the time is the criteria we use to define new species with the concept of time become primary.

From an ephifenomenical point of view, the space and the time both in Biology and in Medicine, don't loose their main role; if it is up to a scientist the choise to manage the time as an essential or derivative impact factor, it is due to stress the structural possibility we have to deal with a matter having both fixed and variable elements, when the framework is an expression of the attempt to classify the two mentioned performative qualia.

It was indeed with Democritus that the variables of the matter were first normologically organized in primaries and fixed elements separated from derivates characteristics, that is to translate, an approval of the collateral hypostatic tendency of human being to perceive differential parameters when the aim is to rationalize the metaphisical counterpart of the matter.

In addition, the component of rationality has to be distinguished if defined on the basis of its usage or the one of its topic.

If it is true that Galileo, Bacon, Descartes ${ }^{8}$ defined the epistemological way to access the knowledge, it has to be distinguished the role of measurement from pure rationalism.

In particular, the usage of reason does not imply measuring but, according to the philosophers, means to guide senses toward an upper knowledge, with an embryonic rational mechanism which is included even within the law level approach to the knowledge.

7 Godfrey Smith, Philosophy od Biology, Princeton University Press, New Jersey, 2014.

8 For an explanation see Abbagnano N. Fornero G, La ricerca del pensiero, 2A, Milano - Torino, Paravia 2015 pp: 111-194.
If it is true that the Cartesian evidence refers to a primary law level discrimination because of the quantity of descriptive elements we decide, at first, to take into consideration, at this point the lack of time would represent a prejudice of the reason but, on the contrary, it is due to point out the inclusion of this component also when observing, within the cartesian "evidence" step.

The observation process in medicine, for example, assumes the rational component to be included at the first step of a generical algoritm, where clinical observation refers to elements we rationally decide not to evaluate because not coherent with a pathology.

In this sense, the time is strictly evaluated as an additional element where its lack does not change the pathogenesis.

More subtly still, the time is considered to be a functional element without wondering about teleonomics.

Functionalism is, infact, when some traits or structures has been selected for and mainteined because it had effect $\mathrm{x}$, but in the case of the time, we should consider it is just a way we have to look at something, effectiveness in its relativism ${ }^{9}$.

Including the time in a functionalist perspective, means to wonder how and what to stress an intrinsecal teleonomic view that, in general, can be extended in each area that substructures our knowledge; it is the case of the History, of the Poetry and the one of the Science, where the time assume a teleological value depending on the perspective (the past, the future, and the present) we onthologically value.

Moving from the impossibility to measure the metaphisical level of the concepts we have just examined, which are functional but erroneously thought to enrich a process they are part of, we firstly admitted the gradual separation of the space and the time from the absolute, to transcribe the usage of them as epiphenomenas in some disciplines.

Thus, to conclude, if we admit mutation, we have to assert the two elements considerated are divisible and if they are, a mathematical attitude to look at the two instances teach they loose the extension without loosing, the metaphisical meaning.

\section{Endonotes}

1. Armocida G, Bicheno E, Fox B (1993) Storia della Medicina. Jaka Book, Milano.

2. Castellani E, Morganti M (2019) La Filosofia della

9 Godfrey p. 60; 64 
Scienza. il Mulino, Bologna.

3. Fanzago tr. It Perrone F (1825) Isitutuzioni patologiche. $2^{\text {nd }}($ Edn.), Da' Torchi di Luca Marotta, Napoli.

4. Gentile, Ronga, Bertelli (2018) Skepsis, Philosophy as research, La Filosofia come ricerca, dalle origini ad Aristotele, edizioni il Capitello, Torino.

5. Godfrey Smith (2014) Philosophy od Biology. Princeton University Press, New Jersey.

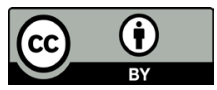

